\title{
A statistical study of diurnal, seasonal and solar cycle variations of F-region and topside auroral upflows observed by EISCAT between 1984 and 1996
}

\author{
C. Foster ${ }^{1}$, M. Lester and J. A. Davies \\ Radio and Space Plasma Physics Group, Department of Physics and Astronomy, University of Leicester, University Road, \\ Leicester, LE1 7RH, UK
}

Received: 19 January 1998 / Revised: 2 June 1998 / Accepted: 3 June 1998

\begin{abstract}
A statistical analysis of F-region and topside auroral ion upflow events is presented. The study is based on observations from EISCAT Common Programmes (CP) 1 and 2 made between 1984 and 1996, and Common Programme 7 observations taken between 1990 and 1995. The occurrence frequency of ion upflow events (IUEs) is examined over the altitude range 200 to $500 \mathrm{~km}$, using field-aligned observations from CP-1 and CP-2. The study is extended in altitude with vertical measurements from CP-7. Ion upflow events were identified by consideration of both velocity and flux, with threshold values of $100 \mathrm{~m} \mathrm{~s}^{-1}$ and $10^{13} \mathrm{~m}^{-2} \mathrm{~s}^{-1}$, respectively. The frequency of occurrence of IUEs is seen to increase with increasing altitude. Further analysis of the field-aligned observations reveals that the number and nature of ion upflow events vary diurnally and with season and solar activity. In particular, the diurnal distribution of upflows is strongly dependent on solar cycle. Furthermore, events identified by the velocity selection criterion dominate at solar minimum, whilst events identified by the upward field-aligned flux criterion dominated at solar maximum. The study also provides a quantitative estimate of the proportion of upflows that are associated with enhanced plasma temperature. Between 50 and $60 \%$ of upflows are simultaneous with enhanced ion temperature, and approximately $80 \%$ of events are associated with either increased F-region ion or electron temperatures.
\end{abstract}

Key words. Ionosphere (auroral ionosphere; particle acceleration)

Correspondence to: C. Foster

${ }^{1}$ Present address: Computer Centre, University of Leicester, University Road, Leicester, LE1 7RH, UK

\section{Introduction}

Over the last two decades, a wealth of radar and satellite observations has revealed that the ionosphere provides a steady and significant source of magnetospheric ions. Among the first radar observations of field-aligned ion upflows in the F-region ionosphere were those made by the Chatanika incoherent scatter radar (Bates, 1974); they were later observed by the EISCAT radar (Winser et al., 1986). Several workers, including Williams and Jain (1986), Jones et al. (1988), Winser et al. (1989), Wahlund and Opgenoorth (1989) and Wahlund et al. (1992), have since presented observations of ion upflows in the F-region and topside ionosphere, with ion velocities ranging from around $100 \mathrm{~m} \mathrm{~s}^{-1}$ to as much as $1500 \mathrm{~m} \mathrm{~s}^{-1}$. Corresponding ion fluxes of up to $10^{14} \mathrm{~m}^{-2} \mathrm{~s}^{-1}$ have been detected, values that are one or two orders of magnitude greater than the classical polar wind flux.

A number of acceleration mechanisms, primarily associated with disturbed ionospheric conditions, have been proposed to account for ion outflows. At high altitudes, transverse acceleration of ions resulting from heating by, for example, ion cyclotron or lower hybrid waves generates outflows with confined pitch angle distributions, so-called ion conics (Ungstrup et al., 1979; Lockwood, 1982). Rocket and satellite observations indicate that ion conics are typically generated above about $1000 \mathrm{~km}$ altitude, often above auroral arcs (Arnoldy et al., 1992). Also, within regions of electron precipitation, field-aligned currents can induce lowfrequency plasma turbulence, which can lead to increased resistivity and hence enhancements in both the electron temperature and the field-parallel electric field. Each effect can induce significant ion acceleration parallel to the geomagnetic field (e.g. Wahlund et al., 1993; Forme et al., 1993; Blelly et al., 1996). Again, such acceleration mechanisms are generally considered to be effective at altitudes above about $1000 \mathrm{~km}$. 
At lower altitudes, other acceleration mechanisms become important. F-region upflows are typically driven by a combination of neutral wind, thermal expansion of the neutral atmosphere resulting from Joule heating, and enhanced diffusion arising from increased F-region ion and/or electron temperatures (Winser et al., 1988; Wahlund et al., 1992; Rodger et al., 1992). Many ion upflow events in the high-latitude F-region ionosphere can be characterised as either "type 1" or "type 2" features, as described by Wahlund et al. (1992). Type 1 events are associated with strong perpendicular electric fields, increased ion temperature resulting from ion frictional heating, and little or no electron precipitation, and may be explained in terms of thermal plasma expansion. Type 2 upflows occur above auroral arcs and are associated with increased electron temperature and field-parallel electric fields.

Keating et al. (1990) presented a statistical study of large F-region field-parallel flows. These authors analysed EISCAT Common Programme 1 data collected between 1985 and 1987 and derived seasonal and diurnal distributions of the occurrence of large field-aligned flows for a range of altitudes between 200 and $500 \mathrm{~km}$. An upflow (or downflow) "event" was deemed to have occurred if either the field-aligned ion velocity exceeded $100 \mathrm{~m} \mathrm{~s}^{-1}$ or the flux was greater than $10^{13} \mathrm{~m}^{-2} \mathrm{~s}^{-1}$. The maximum frequency of occurrence of upward fieldaligned flows was found to occur at 2100 UT, with roughly $50 \%$ of upflows occurring during intervals of enhanced ion temperatures. A greater occurrence of outflows was observed in conjunction with simultaneously enhanced ion and electron temperatures.

Statistical studies based on observations from single instruments, such as the EISCAT radar, can suffer because of the limited latitudinal extent that may be covered. However, the large data bases that are accumulated and the excellent temporal resolution achieved do allow for informative studies of ion upflow events, such as that presented by Keating et al. (1990). Since that particular survey, EISCAT observations have been made over several more years, including topside measurements up to about $1000 \mathrm{~km}$ altitude. Thus it is pertinent to extend the work of Keating and co-authors, in terms of both temporal and altitudinal coverage, to document longer-term variations of ion upflow events. Furthermore, a larger data set should also provide more statistically valid distributions, less affected by "anomalous" observing periods.

This paper presents a statistical study of F-region and topside ion upflow events observed by the EISCAT radar between 1984 and 1996. The occurrence frequency of ion upflow events (IUEs) is studied over the altitude range 200 to $500 \mathrm{~km}$, employing field-aligned observations from Common Programmes One and Two. The study is extended in altitude with measurements from Common Programme Seven obtained between 1990 and 1995. Diurnal and seasonal upflow distributions are first presented and discussed briefly with regard to the findings of Keating et al. (1990). Then, the high-altitude CP-7 observations are considered, followed by an investigation of the occurrence frequency of IUEs as a function of the phase of the solar cycle. Finally, a quantitative study of the relationship between IUEs and enhanced ion and electron temperatures is presented.

\section{Data sets}

For this study, data were collated from EISCAT Common Programmes One, Two and Seven (CP-1, CP-2 and CP-7). CP-1 is a UHF radar experiment in which the beam from the transmitter at Tromsø is aligned approximately along the local geomagnetic field direction. The remote site radars at Kiruna and Sodankylä intersect the Tromsø beam at approximately $300 \mathrm{~km}$ altitude, permitting the measurement of the ion vector velocity within the intersection volume. Some versions of $\mathrm{CP}-1$ also provided such tristatic measurements in the E-region, which are not used in the present study. For the current investigation, longpulse observations from a total of 94 runs of $\mathrm{CP}-1$, taken between January 1984 and February 1996, were employed. In addition to CP-1 measurements, observations from the field-aligned position of 47 runs of CP-2, from May 1984 to March 1996, have been included. In CP-2, the transmitter at Tromsø performs a four-position scan, one of which is vertical and another field-aligned. The dwell-time at each position is $1.5 \mathrm{~min}$, resulting in a cycle time of $6 \mathrm{~min}$. As with $\mathrm{CP}-1$, the remote-site receivers intersect the transmitter beam in the F-region at approximately $300 \mathrm{~km}$ altitude. Only long-pulse measurements were employed in the present study. The length of the long-pulse for both CP-1 and CP-2 experiments is $350 \mu$ s, yielding a range resolution of approximately $52 \mathrm{~km}$ for observations between 150 and $600 \mathrm{~km}$ altitude. The CP-2 data were post-integrated over the dwell-time at the fieldaligned position, whilst the majority of the CP-1 Tromsø data were post-integrated at 5 minutes. Although the study incorporates data from seven versions of $\mathrm{CP}-1$ and four versions of $\mathrm{CP}-2$, together they provide a consistent set of observations suitable for statistical analyses.

It is noted that, due to the curvature of the geomagnetic field-lines, a transmitter beam said to be "field-aligned" is only so over a limited altitude range. The transmitter elevation angles for Common Programmes 1 and 2 are such that the beam is intended to be field-aligned at approximately $300 \mathrm{~km}$ altitude; with increasing distance away from this height, the transmitter beam is only up to about $0.5^{\circ}$ away from the fieldline.

Around 5 y of CP-7 data, obtained from 26 runs between April 1990 and September 1995, were collected to provide vertical observations at F-region and topside altitudes. CP-7 is a monostatic experiment in which the VHF radar, pointing vertically, transmits long-pulses of $750 \mu \mathrm{s}$, yielding a range resolution of approximately $110 \mathrm{~km}$. Under favourable conditions, CP-7 can provide measurements from around $300 \mathrm{~km}$ to perhaps $1500 \mathrm{~km}$ altitude. For the present investigation, it was found that 
observations were obtained consistently for nine range gates between 300 and $800 \mathrm{~km}$ altitude.

\section{Selection criteria for identification of ion upflow events}

Identical criteria to those adopted by Keating et al. (1990) have been used in the present study to define "events" of ion upflow. Thus an upflow was defined as an upward field-aligned flux of greater than $10^{13} \mathrm{~m}^{-2} \mathrm{~s}^{-1}$ and/or an upward field-aligned velocity in excess of $100 \mathrm{~m} \mathrm{~s}^{-1}$. Keating and co-workers (1990) based these threshold values on experience with EISCAT observations of field-aligned flows in the high-latitude ionosphere, which indicate that upflows normally exceed these values only during limited intervals. Keating and co-authors cited observations reported by Jones et al. (1988) and Winser et al. (1989) as examples of such events; more recent observations further justify these selection criteria (e.g. Wahlund et al., 1992). The velocity threshold is greater than values that might be expected due to neutral winds and plasma pressure gradients under quiet conditions, typically a few tens of $\mathrm{m} \mathrm{s}^{-1}$ (Winser et al., 1986; Jones et al., 1988), whilst the flux threshold is an order of magnitude greater than the typical polar wind outflow (Chappell, 1988).

In the present study, for various altitude and time bins the total number of upflow events within each bin was found. These totals were then expressed as a fraction of the total number of observations within each bin, giving a frequency occurrence of upflows as a function of time and height. An "observation" was defined as a single interval of post-integrated data for which estimates of the standard incoherent scatter derived parameters, $\mathrm{N}_{\mathrm{e}}, \mathrm{T}_{\mathrm{e}}, \mathrm{T}_{\mathrm{i}}$ and $\mathrm{V}_{\mathrm{i}}$, were obtained. In addition, the signal-to-noise ratio was required to be greater than $2 \%$. Using the uncertainty approximations of Du Castel and Vasseur (1972), a signal-to-noise ratio of $2 \%$ yields an uncertainty of around $25 \%$ in the ion and electron temperature values derived from CP-1 Tromsø observations. The generally poorer signal quality received from the farther range gates therefore resulted in fewer observations at higher altitudes. This selection technique differs from that used by Keating et al. (1990). These authors defined an observation simply as a single post-integration period, thus obtaining the same number of observations regardless of altitude.

\section{Results and discussion}

The initial study examined $12 \mathrm{y}$ of EISCAT field-aligned measurements derived from Common Programmes One and Two. Observations from six altitude ranges were binned at hourly intervals, the range gates being centred approximately at 200, 250,300,350, 400 and $500 \mathrm{~km}$ altitude. These ranges match those employed by Keating et al. (1990), and thus afford a direct comparison of results. Times throughout are given in Universal Time
(UT), which at the location of the EISCAT transmitter is approximately two hours behind magnetic local time (MLT).

\subsection{Diurnal variation of upflows: 200 to $500 \mathrm{~km}$}

Figure 1 illustrates the diurnal distributions of ion upflow events as a function of UT and altitude for six range gates between 200 and $500 \mathrm{~km}$. The histograms indicate the percentage occurrence of upflow events within hourly bins, scaled according to the left-hand axes. In addition, each bar is subdivided into three sections. The white (lower) portion of each represents the proportion of events where the upward field-aligned flux exceeded $10^{13} \mathrm{~m}^{-2} \mathrm{~s}^{-1}$ but where the upward velocity was less than $100 \mathrm{~m} \mathrm{~s}^{-1}$. Similarly, the proportion of events selected only according to the velocity threshold is represented by the light grey (middle) portion. Events which satisfied both the velocity and flux selection criteria are represented by the dark grey (upper) portion. Finally, the solid lines indicate the total number of observations in each bin at each altitude, scaled according to the right-hand axes. Thus not only is the variation of upflow occurrence frequency with UT and altitude demonstrated, but also the relative proportions of the different "types" of event and the dependence on height of the number of observations obtained. Note that when referring to events of different "types" there is no intended implication that they are generated by different processes; an event of a particular type merely indicates by which of the three selection criteria it was identified.

Figure 1 illustrates how the type of upflow event varies with height. Up to $300 \mathrm{~km}$ altitude, the majority of all events exhibit fluxes above the specified threshold value but with upward velocities of less than $100 \mathrm{~m} \mathrm{~s}^{-1}$. However, beyond $350 \mathrm{~km}$ altitude the occurrence of large velocities increases steadily, indicated by the light grey portion of each bar. The percentage occurrence of flux-only events peaks around 2100 UT at $400 \mathrm{~km}$ and is then slightly reduced in the highest range gate. However, greater numbers of large fluxes are observed with increasing altitude if those which are also accompanied by velocities above the threshold value are considered, as revealed by the dark grey portion of each bar.

Figure 1 demonstrates that the number of upflows tends to increase monotonically with altitude, reaching a maximum of approximately $23 \%$ around 2200 UT (or about midnight MLT) at $500 \mathrm{~km}$. Upward velocities in excess of $100 \mathrm{~m} \mathrm{~s}^{-1}$ are uncommon below 350 $\mathrm{km}$ altitude, but become increasingly likely with increasing height. Large field-aligned velocities are detected by the EISCAT radar up to approximately $12 \%$ of the time at $500 \mathrm{~km}$ altitude, either alone or in conjunction with large upward fluxes. Upward fieldaligned fluxes of greater than $10^{13} \mathrm{~m}^{-2} \mathrm{~s}^{-1}$ occur less than $5 \%$ of the time below $250 \mathrm{~km}$, but the occurrence frequency of such events increases with altitude, reaching a maximum of $15 \%$ at $500 \mathrm{~km}$. Finally, upflows are in general observed by EISCAT between $15 \%$ and $20 \%$ 

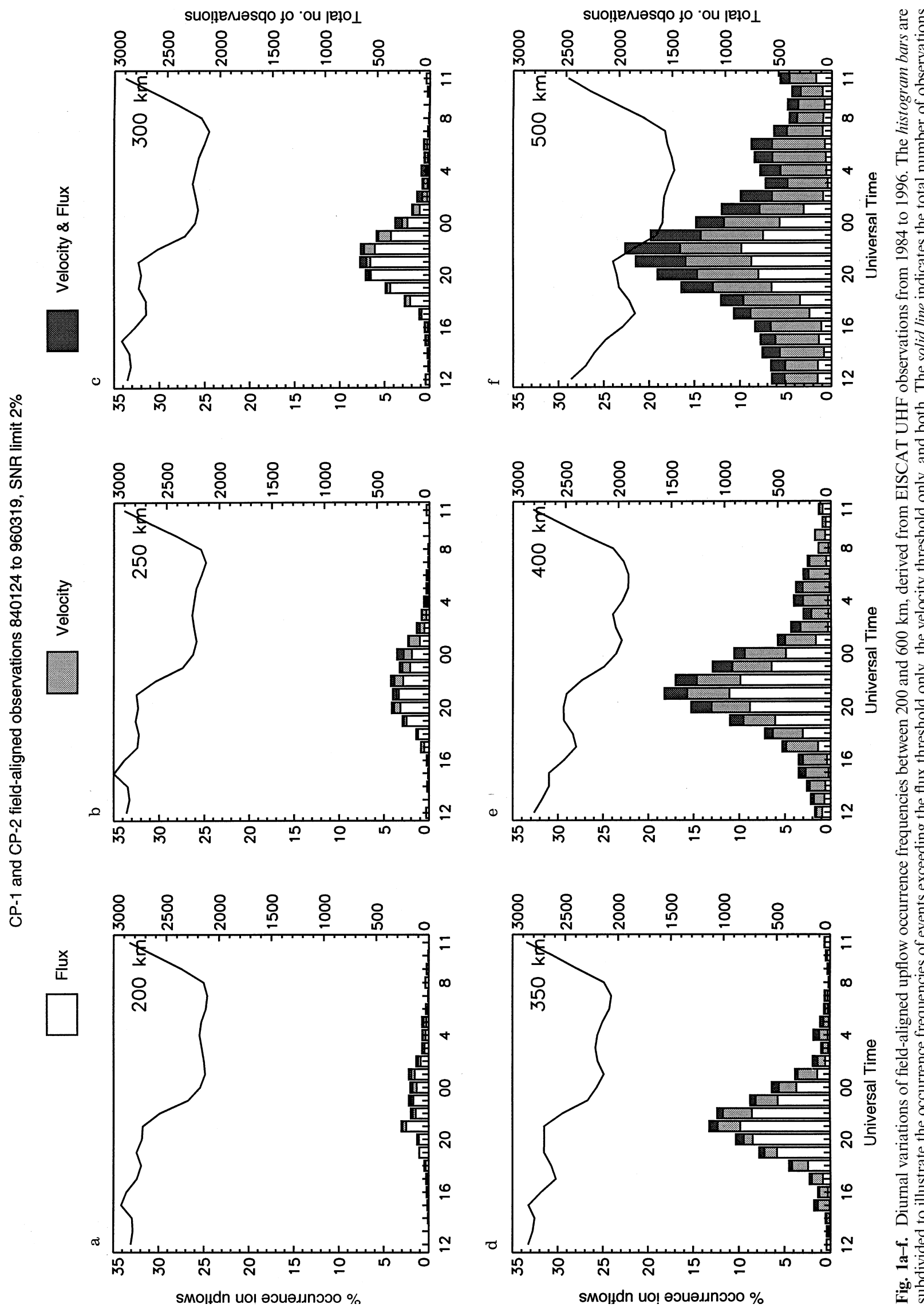

$\ll$

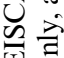

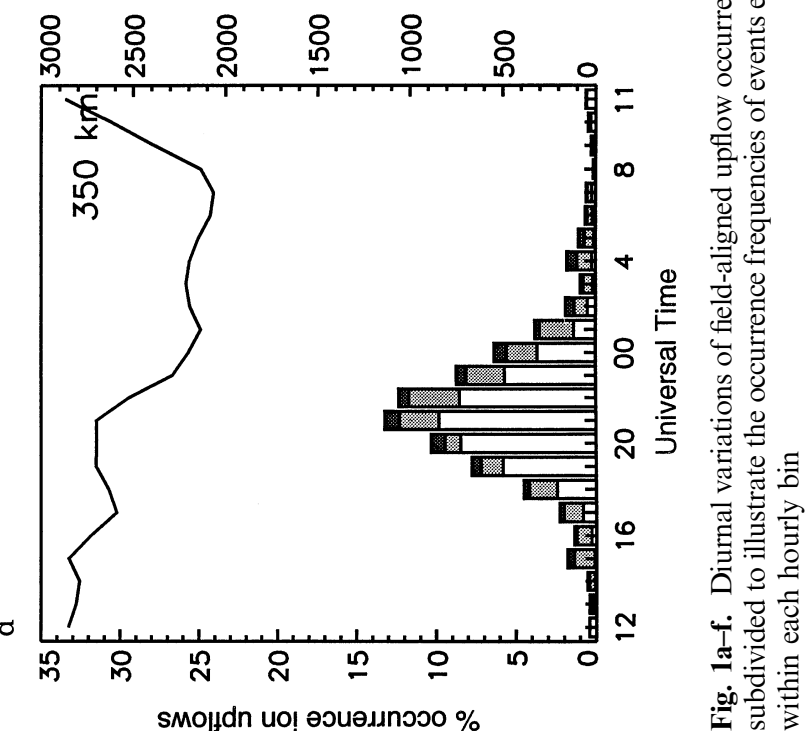


of the time in the pre-midnight sector between 400 and $500 \mathrm{~km}$ altitude.

The measurements contributing to Fig. 1 were all obtained from a single geomagnetic latitude. Previous statistical analyses of satellite data (e.g. Ghielmetti et al., 1978; Loranc et al., 1991) have revealed that the spatial distribution of upflows is auroral oval-like. A statistical study of transversely accelerated ions (TAIs), and subsequent ion upflow, by Klumpar (1979) revealed a similar distribution of events, although the author reported ion fluxes that were one to two orders of magnitude less than those observed in the present study. Other statistical analyses of satellite data indicate that upflows occur mostly in the cusp region (Yau et al., 1984; Abe et al., 1993). Hence, the variation evident in Fig. 1 would be unexpected if the radar observed within the auroral oval at all times. However, on the day-side the auroral oval is typically positioned at higher geographical latitudes than the EISCAT transmitter (beyond around $70^{\circ} \mathrm{N}$ between about 0600 to $1800 \mathrm{UT}$ ) whilst on the night-side the auroral oval typically extends to below $69^{\circ} \mathrm{N}$ and the EISCAT facility is then within a region where higher upflow occurrence is expected. Therefore, the observed UT variation may reflect a spatial rather than a temporal variation. On the other hand, Klumpar (1979) concluded that outflows were a predominantly night-side phenomenon at auroral zone latitudes, hence there is probably both a local time and latitudinal variation in the distribution of upflows, both of which influence the distributions of Fig. 1. Combined temporal and spatial effects are difficult to resolve from single-point measurements such as those derived from EISCAT radar observations.

These findings are in broad agreement with the results of a similar analysis by Keating et al. (1990) of three years of EISCAT data. These authors noted an increase in upflow occurrence with height, but found that the upflow occurrence maximised between 400 and $500 \mathrm{~km}$ altitude, reaching about $16 \%$ between 2100 and 2200 UT. In addition, the UT variation in occurrence frequency was less well defined than in the present study, particularly above the $300 \mathrm{~km}$ range gate. These differences are likely due to the different descriptions of an "observation" adopted in the two studies. The definition used in the present case results in the number of observations decreasing with altitude. Keating and coauthors (1990) also obtained maximum upflow frequencies that were smaller at all heights than observed in the present study. This difference is a real effect of the extended data set used in this study, since the data used by Keating and co-authors were representative of solar minimum conditions.

\subsection{Seasonal variation of upflows: 200 to $500 \mathrm{~km}$}

Seasonal distributions of ion upflow events in the same six altitude bins are presented in Fig. 2. There is considerable variation over the year in the number of observations at each altitude, with up to 6000 measurements around March and September and fewer than
1000 in December at the highest altitude. The total number of observations in the $200 \mathrm{~km}$ range gate approached 60000 , some four times that available for the study of Keating et al. (1990).

A seasonal variation in upflow occurrence frequency, at least at 350 and $400 \mathrm{~km}$ altitude, is seen in Fig. 2. Upflows were detected in slightly more than $10 \%$ of observations in January and December, that figure falling to about $3 \%$ in June and July at $400 \mathrm{~km}$. There is no clear evidence of such a seasonal dependence at the lower ranges. However, there is some evidence of a winter increase in the $500 \mathrm{~km}$ range gate, although this is less pronounced than at $400 \mathrm{~km}$ due to higher upflow occurrence in the summer months. The $500 \mathrm{~km}$ distribution is further marked by a high occurrence of upflows in October. The $400 \mathrm{~km}$ distribution also reflects a relatively large October value, suggesting that there is a real increase in the number of upflows detected during that month.

Considering the occurrences of the different types of event, similar conclusions can be drawn as from Fig. 1. Throughout the year, the number of flux events tends to increase steadily with altitude, maximising in the 400 and $500 \mathrm{~km}$ range gates. Below $350 \mathrm{~km}$ altitude, the frequency of flux events exhibits little seasonal variation. The occurrence frequency of large upward field-aligned velocities is small up to $300 \mathrm{~km}$; above that height these events are progressively common with increasing altitude.

Keating et al. (1990) also examined the variation of upflow occurrence as a function of season and altitude. Figure 2 reveals distributions similar to those of Keating et al. (1990) up to the $300 \mathrm{~km}$ range gate. At $350 \mathrm{~km}$, however, the present study reveals a higher upflow occurrence frequency in December, January and February, maximising at around $7 \%$. The seasonal variation in upflow occurrence was observed by Keating and coauthors, but was perhaps less pronounced than in the present study. At $500 \mathrm{~km}$ altitude there was no apparent winter increase in upflow occurrence in the Keating study; rather, maxima of up to $16 \%$ were observed in March, August and September, with the January occurrence down to less than 2\%. Keating et al. (1990) indicated that the small number of winter observations may have rendered these data less statistically significant, but concluded that there was a fairly clear winter dependence. These authors also noted an occurrence maximum in the July bin at $400 \mathrm{~km}$, which was attributed to a particularly large number of upflow events detected during July of 1987. The larger data set available for the present investigation further demonstrates the anomalous nature of those particular results of Keating and co-workers and the need for a detailed extended study.

It is noted that there was little observed variation in the UT distributions of the total number of observations as a function of month (not illustrated). Therefore, the observed seasonal variations in upflow occurrence frequency are not a consequence of data sampling bias.

In general, upflow occurrence frequency is greater with increasing altitude. Upward field-aligned velocities 


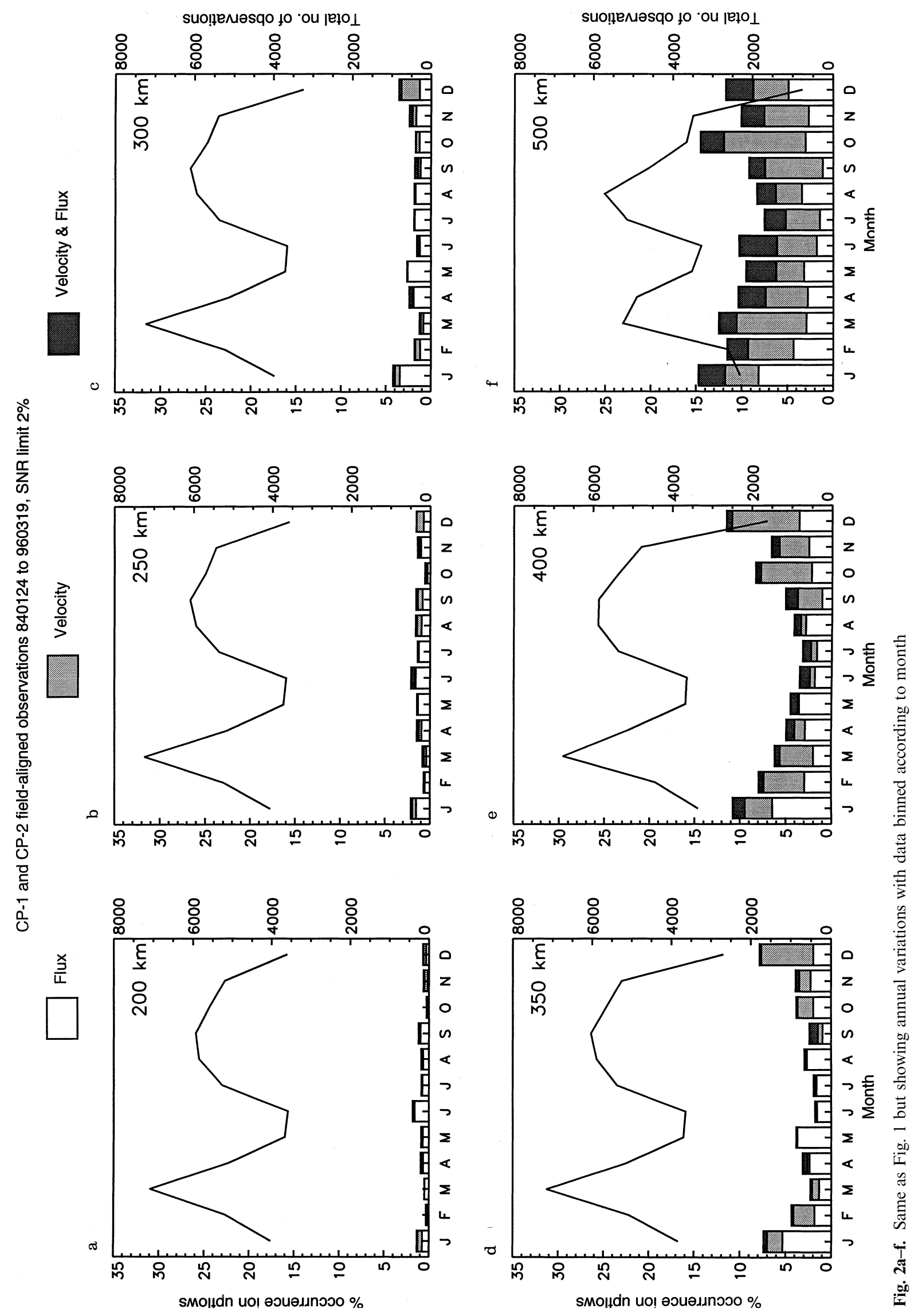


in excess of $100 \mathrm{~m} \mathrm{~s}^{-1}$ are typically only detected above $300 \mathrm{~km}$, but flux events are observed at all heights. More upflows were detected during the winter months above $300 \mathrm{~km}$, an observation which is in agreement with the studies of Klumpar (1979) and Keating et al. (1990).

\subsection{Diurnal variation of upflows: 300 to $800 \mathrm{~km}$}

The results thus far indicate that the frequency of ion upflow events tends to increase monotonically with height, at least between 200 and $500 \mathrm{~km}$. The higher altitude is effectively an upper range limit for the analysis, since the EISCAT radar experiments CP-1 and CP-2 seldom provide reliable field-aligned observations above this altitude. However, higher altitude vertical observations are available from the VHF radar experiment CP-7. Around five years of CP-7 data, obtained between April 1990 and September 1995, were analysed to generate occurrence distributions of upflows as a function of UT and altitude. In this case, six range gates spaced at $100 \mathrm{~km}$ intervals between 300 and $800 \mathrm{~km}$ were considered.

As before, an upflow event was defined as an upward velocity in excess of $100 \mathrm{~m} \mathrm{~s}^{-1}$ or an upward flux greater than $10^{13} \mathrm{~m}^{-2} \mathrm{~s}^{-1}$. However, it should be emphasised that parameters obtained from CP-7 are derived from vertical observations, not field-aligned. Hence the distributions illustrated in Fig. 3 represent the frequency occurrence of vertical upflow events.

The distributions for 300,400 and $500 \mathrm{~km}$ altitude in Fig. 3 differ from those for the same ranges derived from the CP-1 and CP-2 observations, illustrated in Fig. 1. A greater occurrence of upflows is evident in the CP-7 data, which also exhibit more day-side events. Furthermore, the occurrence maxima lie between 0000 and $0200 \mathrm{UT}$, as opposed to the pre-midnight maxima noted previously. It is noted that there is no significant difference in the UT distributions of the total number of observations for CP-1/2 and for CP-7, represented by the solid lines in Figs. 1 and 3, respectively. Hence the differences in the CP-1/2 and CP-7 upflow occurrence distributions are not a consequence of data sampling bias.

To examine the extent to which the vertical pointing direction could account for these differences, the analysis was also performed on the vertical observations from the CP-2 experiment. It was first established that the $\mathrm{CP}-2$ field-aligned observations are a representative subset of the data set. Subsequently, diurnal distributions of upflows were derived from CP-2 vertical observations. It was found that these vertical upflow distributions were more akin to those derived from the CP-7 data (Fig. 3) than from the field-aligned observations (Fig. 1). The CP-2 vertical distributions exhibited upflow occurrence maxima around or after midnight, as seen with the CP-7 observations, rather than premidnight as with the field-aligned observations. Thus it is concluded that the distributions derived from the CP7 data are indeed characteristic of the vertical pointing direction employed in the experiment.
There are components of the field-perpendicular zonal $\left(\mathbf{V}_{\perp \mathrm{E}}\right)$, meridional $\left(\mathbf{V}_{\perp \mathrm{N}}\right)$ and field-aligned $\left(\mathbf{V}_{\|}\right)$ ion velocities in the vertical direction. The vertical component of $\mathbf{V}_{\perp \mathrm{E}}$ is typically small, perhaps only a few $\mathrm{m} \mathrm{s}^{-1}$, since the geomagnetic declination is near to zero degrees. Thus the vertical velocity, $\mathrm{V}_{\mathrm{i}}$, may be approximated by the expression

$\mathbf{V}_{\mathrm{i}}=\mathbf{V}_{\|} \cos \mathrm{I}+\mathbf{V}_{\perp \mathrm{N}} \sin \mathrm{I} \cong 0.98 \mathbf{V}_{\|}+0.2 \mathbf{V}_{\perp \mathrm{N}}$

where $I$, the magnetic dip angle at the altitude of the measurements, is approximately $12^{\circ}$. Hence if the meridional component of velocity, $\mathbf{V}_{\perp \mathrm{N}}$, is small with respect to the field-aligned component, $\mathbf{V}_{\|}$, the measured vertical velocity is indeed representative of that in the field-aligned direction. However, comparing the upflow distributions for $\mathbf{V}$ and $\mathbf{V}_{\mathrm{i}}$ (Figs. 1 and 3, respectively) it is clear that the field-aligned and vertical velocities are dissimilar, and therefore that the vertical component of $\mathbf{V}_{\perp \mathrm{N}}$ is typically non-negligible during plasma upflow. The present analysis has therefore revealed that, in general, field-aligned velocities cannot be inferred from vertical observations.

EISCAT CP-1 and CP-2 provide tristatic measurements of ion velocity at the intersection altitude of the three receiver beams, from which the components of velocity parallel and perpendicular to the geomagnetic field may be derived. If all available measurements of $\mathbf{V}_{\perp \mathrm{N}}$, from approximately $300 \mathrm{~km}$ altitude, are collated and binned at hourly intervals there is a clear diurnal variation in the median meridional component of ion velocity, with typically southward values between 1200 and 2300 UT and northward values at other times (not illustrated). The maximum (median) southward velocity of nearly $100 \mathrm{~m} \mathrm{~s}^{-1}$ occurs around $2000 \mathrm{UT}$; at this time more than $75 \%$ of all calculated velocities are southward. Subsequently, velocities become increasingly northward with the median value peaking at about $50 \mathrm{~m} \mathrm{~s}^{-1}$ around $0200 \mathrm{UT}$.

A southward meridional velocity will act to reduce the observed vertical velocity, whilst a northward flow will have the opposite effect. Thus, in general, the vertical velocity will be reduced between about 1200 and 2300 UT and enhanced at other times. This effect may account for the reduced detection of vertical upflows before midnight and the shift of the maximum occurrence to post-midnight. This is at least true at $300 \mathrm{~km}$, the altitude for which tristatic measurements were available.

The influence of $\mathbf{V}_{\perp \mathrm{N}}$ on the observed vertical velocity was examined quantitatively for the tristatic $300 \mathrm{~km}$ range gate. Initially, vertical velocities were derived from the field-parallel and meridional velocity components for all field-aligned CP-2 data. Then, a frequency distribution of upflows, based on the calculated vertical velocities, was derived as before, and is presented in Fig. 4a. For comparison, the distribution obtained from the CP-2 observed vertical velocities is included in Fig. 4b. Although the peak values in Fig. 4a, b differ (16\% compared to $12 \%$, respectively), the similarity in shape between the two distributions indicates that the vertical observations are significantly affected by the 

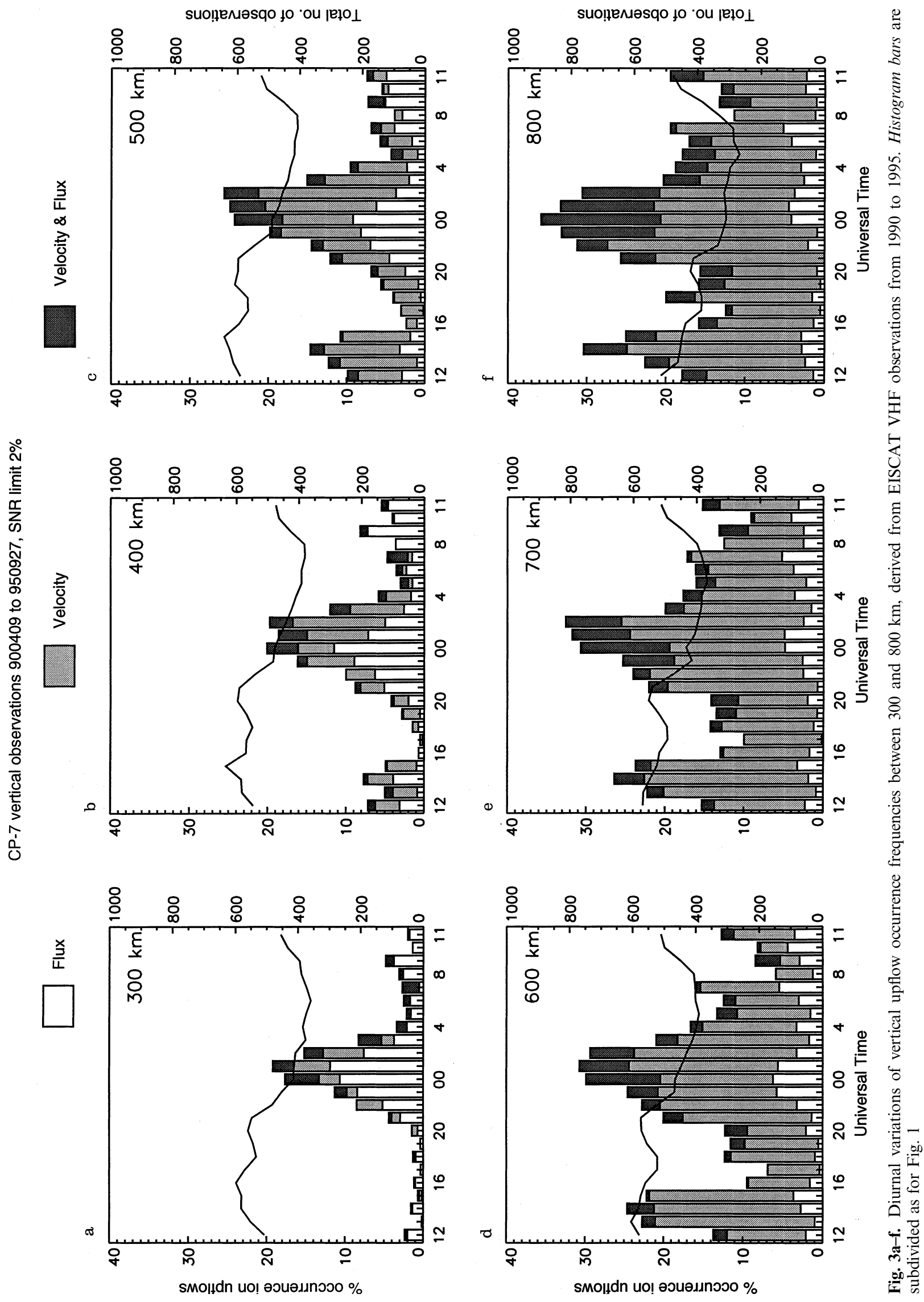
CP-2 vertical observations, SNR limit $2 \%$ 850410 to 960319
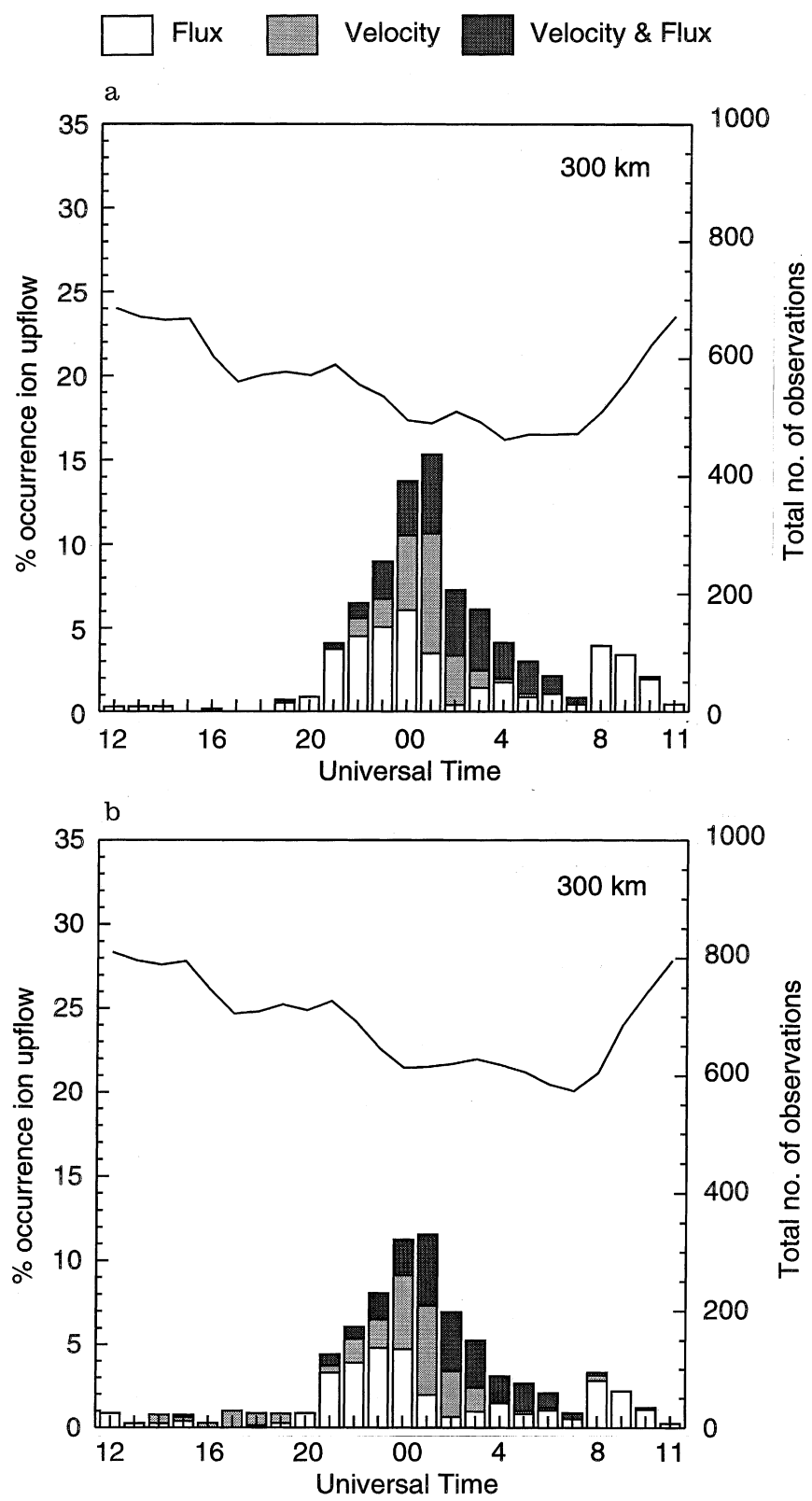

Fig. 4. a Diurnal distribution of vertical upflows derived from vertical velocities calculated from CP-2 tristatic measurements of $\mathbf{v} \perp \mathrm{N}$ and $\mathbf{v}$. b Diurnal distribution of upflows derived from $\mathrm{CP}-2$ vertical observations

meridional velocity component, suggesting also that this is the sole cause of the different distributions obtained from field-aligned and vertical observations. It is supposed that the vertical observations at higher altitudes are similarly affected, although this cannot be tested since measurements of the velocity components are only available at the F-region tristatic altitude of around $300 \mathrm{~km}$. Hence the effect of $\mathbf{V}_{\perp \mathrm{N}}$ on the vertical observations accounts for the shift of the peak of the vertical upflow distribution to post-midnight. However, the distributions of Fig. 3 also indicate an increased occurrence of day-side events above $300 \mathrm{~km}$ altitude, between about 0900 and $1500 \mathrm{UT}$. Since $\mathbf{V}_{\perp \mathrm{N}}$ at $300 \mathrm{~km}$ is typically between only +20 and $-30 \mathrm{~m} \mathrm{~s}^{-1}$ during this interval, and there are few day-side events at that height, it might be concluded that the meridional component of velocity attains greater values at higher altitudes. Since the $\mathbf{E} \times \mathbf{B}$ drift is approximately constant along the geomagnetic field line over the range of altitudes considered, this could only occur if there were a latitudinal gradient in $\mathbf{V}_{\perp N}$, which would result in different meridional velocities being observed at different altitudes along the vertical line-of-sight.

It is concluded that, if the vertical observations could be corrected to account for the effect of $\mathbf{v}_{\perp \mathrm{N}}$, then the upflow occurrences derived from the CP-7 data would exhibit a similar diurnal variation to those for lower altitudes. It is not clear, though, why a greater occurrence of upflows is detected in CP-7 data than is observed in CP-2 observations at similar heights. Notwithstanding the problems associated with vertical observations, the CP-7 data reveal progressively greater frequency occurrences of upflow events with increasing altitude.

\subsection{Variation of upflows over one solar cycle}

The current data set of CP-1 and CP-2 observations extend over an interval in excess of $12 \mathrm{y}$, permitting an examination of the relationship between upflow occurrence and solar cycle. The data have been binned according to altitude and year, and percentage occurrences of upflow events calculated for each bin, as described in Sect. 2. It is noted that there is little variation in the diurnal distribution of the total number of observations as a function of year, as illustrated by the solid lines in Fig. 6. Therefore, there is no sample bias in the upflow occurrence distributions presented in Figs. 5 and 6.

Figure 5 illustrates the variation by year of upflow occurrence at $400 \mathrm{~km}$ altitude for the period between January 1984 and March 1996. This range-gate was selected since upflows are observed relatively frequently at this altitude, whilst the total number of observations is not reduced significantly. Although 13 one-year bins are included in Fig. 5, that for 1996 was derived from data from only two experiments and is therefore less representative of the year than the other bins. The figure reveals a clear dependence on year of the type of upflow event observed. Between 1988 and 1992 the majority of events exhibited fluxes above the threshold value, whilst during this period there were very few velocity events, and only a small proportion of the upflows exhibited both large fluxes and velocities. However, the opposite situation is apparent for the remaining intervals, namely 1984 to 1987 and 1993 to 1996, when few events exhibited fluxes above the threshold value and most of the events were selected since they exceeded the velocity criterion. It was noted that a similar distribution (not illustrated), albeit with reduced upflow frequencies, was obtained when the flux and velocity threshold values were increased to $2 \times 10^{13} \mathrm{~m}^{-2} \mathrm{~s}^{-1}$ and $200 \mathrm{~m} \mathrm{~s}^{-1}$, 
CP-1 and CP-2 field-aligned observations, SNR limit 2\% 840124 to 960319

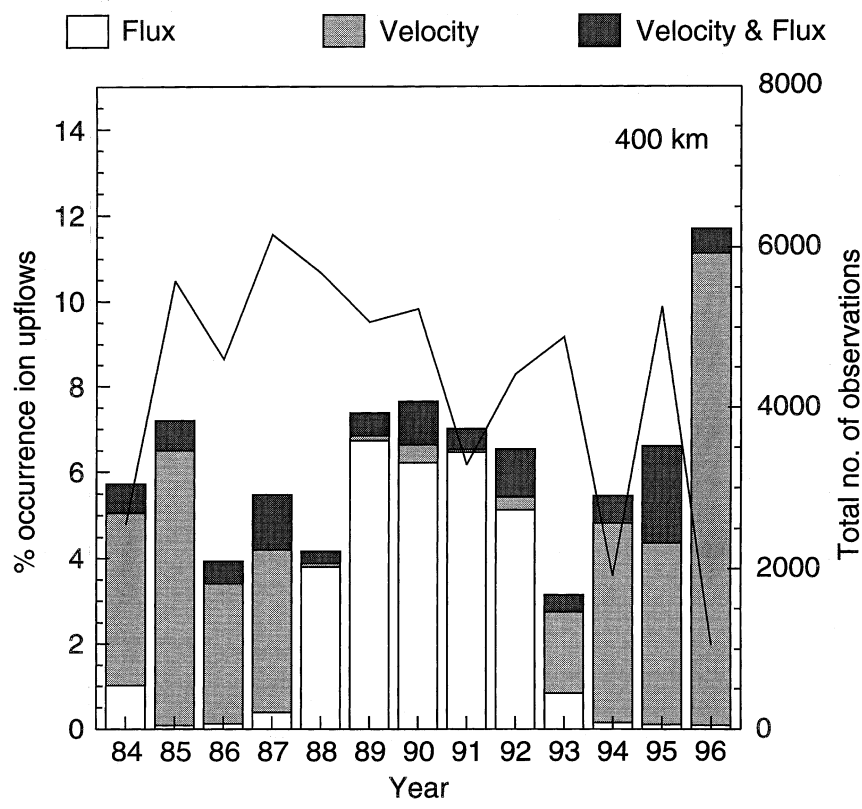

Fig. 5. Frequency occurrence of upflows as a function of year between 1984 and 1986 at 400-km altitude. Histogram bars are subdivided as for Fig. 1 respectively, demonstrating that the clear variation in the type of event is not a consequence of an arbitrary selection criteria.

The period from around late 1987 to the middle of 1993 corresponded to the more active period of solar cycle 22 , "active" here signifying a sunspot number $\left(\mathrm{R}_{\mathrm{z}}\right)$ of greater than about 50. The remaining intervals covered by the present data set, however, fell within the less active periods of solar cycles 21 and 22. These loosely-defined intervals of high and low solar activity correspond well to the changes in upflow characteristics documented already, with flux events predominant during generally active solar conditions and velocity events prevalent at other times.

Previous studies have demonstrated that the magnitude and composition of ionospheric outflows are dependent on solar cycle. For example, Yau et al. (1985) presented a statistical analysis of auroral and polar ion outflows in the energy range $10 \mathrm{eV}$ to $17 \mathrm{keV}$, as detected by the DE-1 satellite. The study examined the interval from September 1981 to May 1984, coincident with the descending phase of solar cycle 21. Yau and co-authors concluded that the $\mathrm{O}^{+}$outflow rate for the period of greater solar activity between 1981 and 1982 was a factor of two larger than the outflow rate between 1983 and 1984. It was also noted that variations in $\mathrm{H}^{+}$outflow rate were not statistically significant.

CP-1 and CP-2 field-aligned observations, SNR limit 2\%

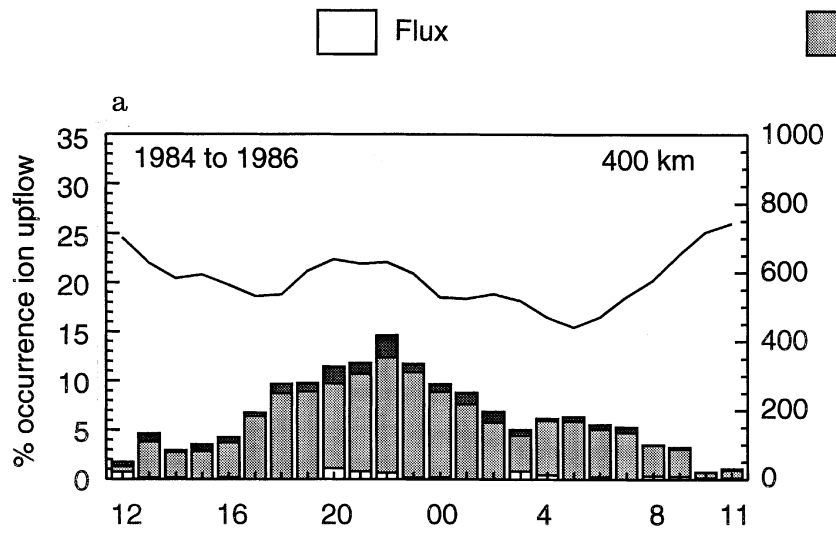

Velocity

Velocity \& Flux
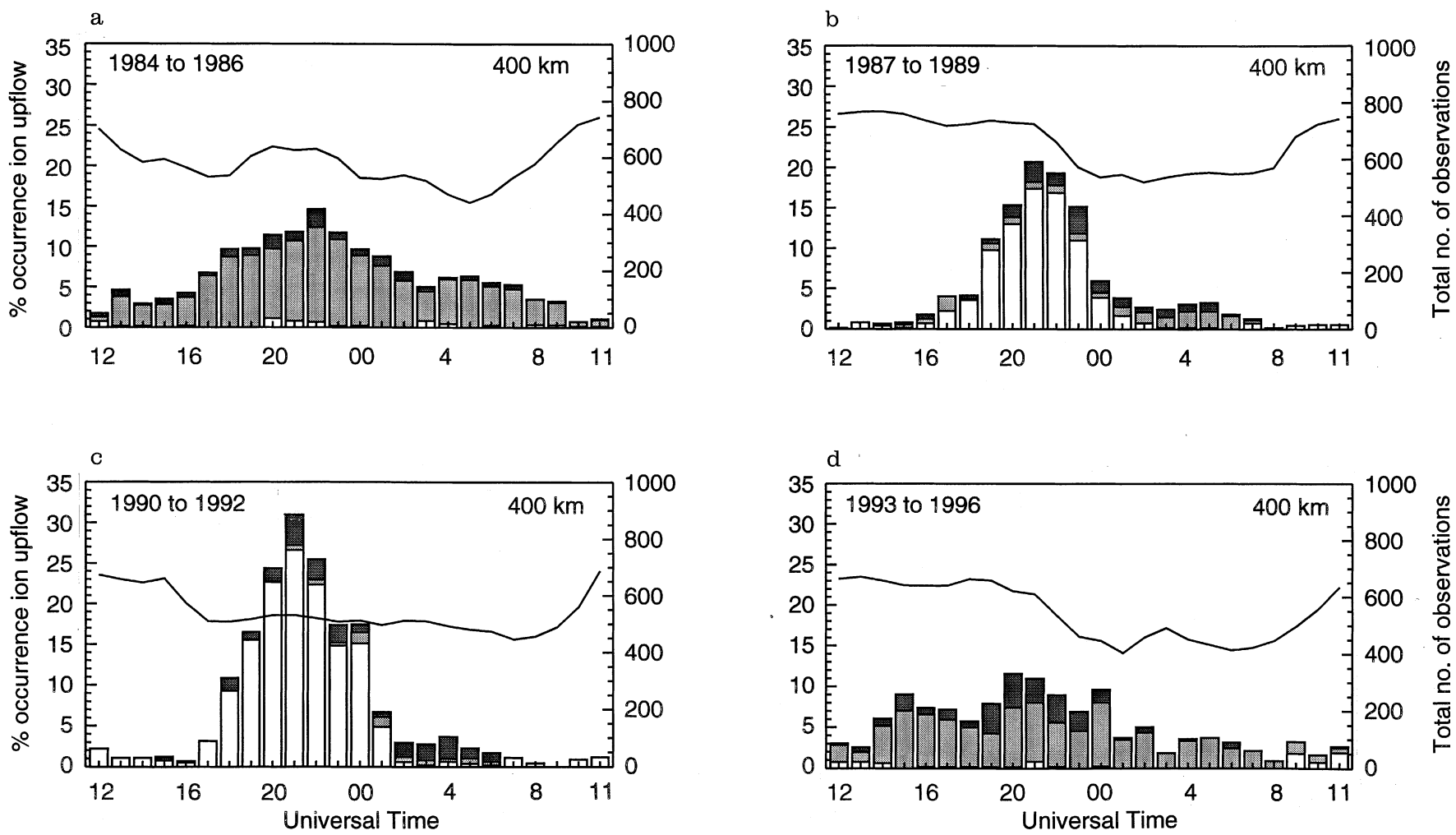

Fig. 6a-d. Same as Fig. 1 but with observations further divided into four three-year bins, illustrating the variation in the diurnal upflow occurrence distribution over one solar cycle 
Hence, typically greater outflow fluxes, consisting primarily of $<1 \mathrm{keV}$ ions, were observed during active solar conditions.

The dependence of IUEs on solar cycle is also evident in the diurnal distributions of upflows when observations at a single altitude are sub-divided into three-year bins, as illustrated by Fig. 6. This figure simply presents the data from Fig. 1e, but with the data divided into four bins of three years. Note that the last panel also includes data from 1996, for which year there are only a few hours of data. It is evident from Fig. 6 that there is indeed a significant variation with solar phase on both the type of upflow detected and on the diurnal distributions of the events. During more active solar conditions, represented by Fig. 6b, c, the majority of events exceed the flux threshold only. There are more upflows in general during these periods, reaching a $30 \%$ occurrence frequency for the period 1990 to 1992 , compared with about 15\% between 1984 and 1986. Furthermore, broader distributions are observed during quieter solar conditions, as illustrated by Fig. $6 \mathrm{a}$, d. Indeed, the familiar diurnal variation of upflows is scarcely evident from the observations made between 1993 and 1996.

In conclusion, both the distributions of upflows and the type of event exhibit a strong dependence on solar cycle. The diurnal distributions presented by Keating et al. (1990) were derived from observations taken between 1985 and 1987, and are therefore representative of the ascending phase of solar cycle 22 . However, as indicated by Fig. 6, markedly different distributions could have been obtained from a different sample data set.

Keating et al. (1990) suggested that many supposed upflow events detected at altitudes above $400 \mathrm{~km}$ were, in fact, due to large scatter in derived velocity and flux values, arising from reduced signal-to-noise ratios high altitudes. It is possible, then, that some of the "velocity" upflows identified during less active solar conditions may have resulted from greater errors in the derived parameters, since during such times the SNR is adversely affected by relatively low electron densities. As remarked by Keating et al. (1990), quantifying an appropriate SNR threshold is problematical. The value of $2 \%$ employed in the present study was arrived at after examination of a number of samples from the entire data set. A similar SNR limit was adopted by Davies et al. $(1997,1998)$ to eliminate "unreliable" estimates of ion velocity derived from $\mathrm{CP}-1$ and $\mathrm{CP}-2$ observations. Re-examination of the data presented in Fig. 6 indicated that SNR thresholds of up to $10 \%$ resulted in a decrease in the proportion of velocity events detected, but had little effect on the observed frequency of flux events, as might be expected since the electron density is likely to be greater in the latter case. Importantly, though, sufficient numbers of events of both types remained such that the variation with solar phase was still apparent.

The predominance of flux events during more active solar conditions is likely due to the higher ambient electron densities prevalent at these times (e.g. Davies, 1990), since the calculated flux is simply the product of the observed electron density and field-aligned ion velocity. However, it is not obvious why there is also a decrease in the occurrence frequency of large upward field-aligned velocities during such times. Essentially, an increase in the electron density is accompanied by a reduction in the upward plasma velocity. Variations in the electron density affect the pressure gradient, gravity and frictional forces in the field-parallel ion momentum balance equation. The field-aligned pressure profile is also a function of both ion and electron temperatures, which also vary with solar activity. Hence the degree of solar activity will have a complex effect on the fieldaligned ion momentum and the precise causes for the variation in type of event are not immediately apparent. However, it is evident that the nature and occurrence of upflows are indeed dependent on solar cycle. These observations were only made possible by considering separately the selection criteria adopted for the identification of upflow events, and through the study of the large database of EISCAT observations.

We conclude that during the more active phase of the solar cycle the majority of upflow events are characterised by enhanced field-aligned fluxes and modest fieldaligned velocities. Conversely, during quieter solar conditions, large upward field-aligned fluxes are rarely observed and intervals of enhanced field-aligned velocities are more common. Furthermore, upflow events in general are more frequently observed during solar maximum than solar minimum.

\subsection{Upflow occurrence and ion frictional heating}

A number of studies, for example Heelis et al. (1993), Wilson (1994), Wahlund et al. (1992) and Liu et al. (1995), have demonstrated that F-region ion frictional heating may contribute to the production of upward plasma flows. At high-latitudes, enhanced convection electric fields, which often exceed $100 \mathrm{mV} \mathrm{m}^{-1}$, can drive the ions at large velocities relative to the neutral atmosphere, resulting in heating of the ions through frictional contact with the neutrals. Increased ionneutral coupling below about $120 \mathrm{~km}$ altitude tends to inhibit large ion-neutral relative velocities. The response of the ion temperature is almost instantaneous and fieldaligned ion acceleration can result as a consequence of the modified plasma pressure gradient. Ion frictional heating has been described by, for example, Rees and Walker (1968), St.-Maurice and Schunk (1979).

Figure 7 illustrates the occurrence distributions of upflows which are simultaneous with ion frictional heating at $300 \mathrm{~km}$ (Fig. 7a) and $400 \mathrm{~km}$ altitude Fig. $7 \mathrm{~b}$. "Simultaneous" here means that the interval of ion heating and the upflow occurred within the same postintegration. An event of ion frictional heating was identified as an enhancement in the field-parallel ion temperature of more than $100 \mathrm{~K}$ above its ambient value. This criterion is based on the work of McCrea et al. (1991) and Davies et al. (1997). The ambient ion temperature is simply the modal value at each altitude over each experiment run, an appropriate definition 


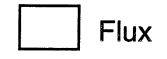

a
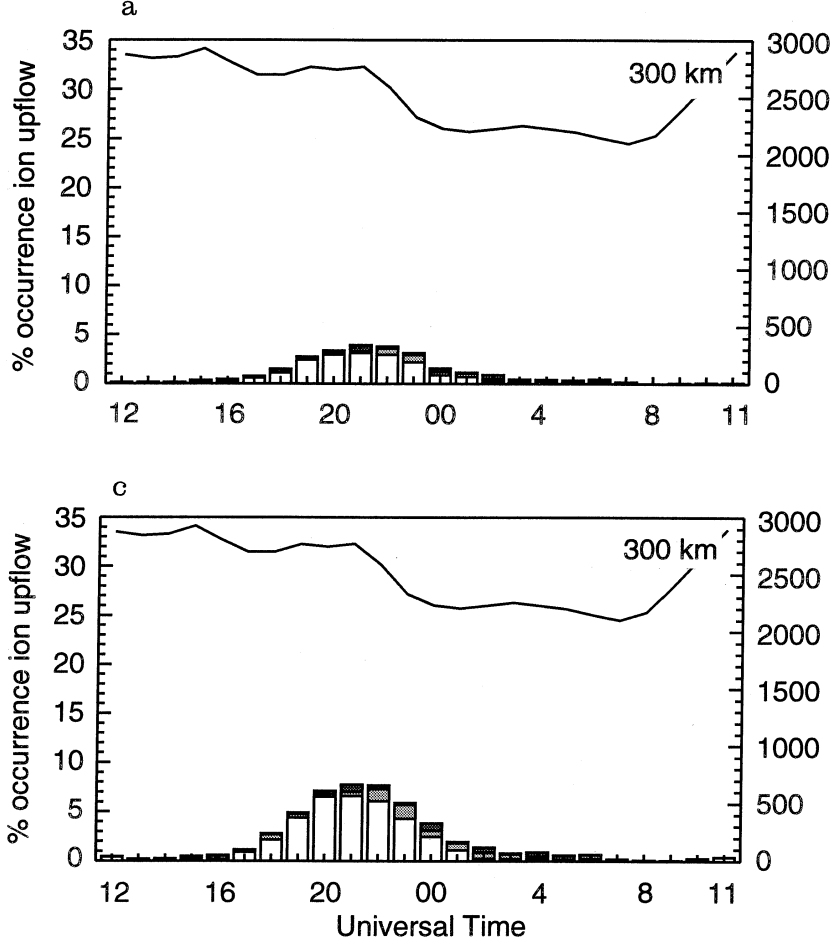

Velocity

Velocity \& Flux
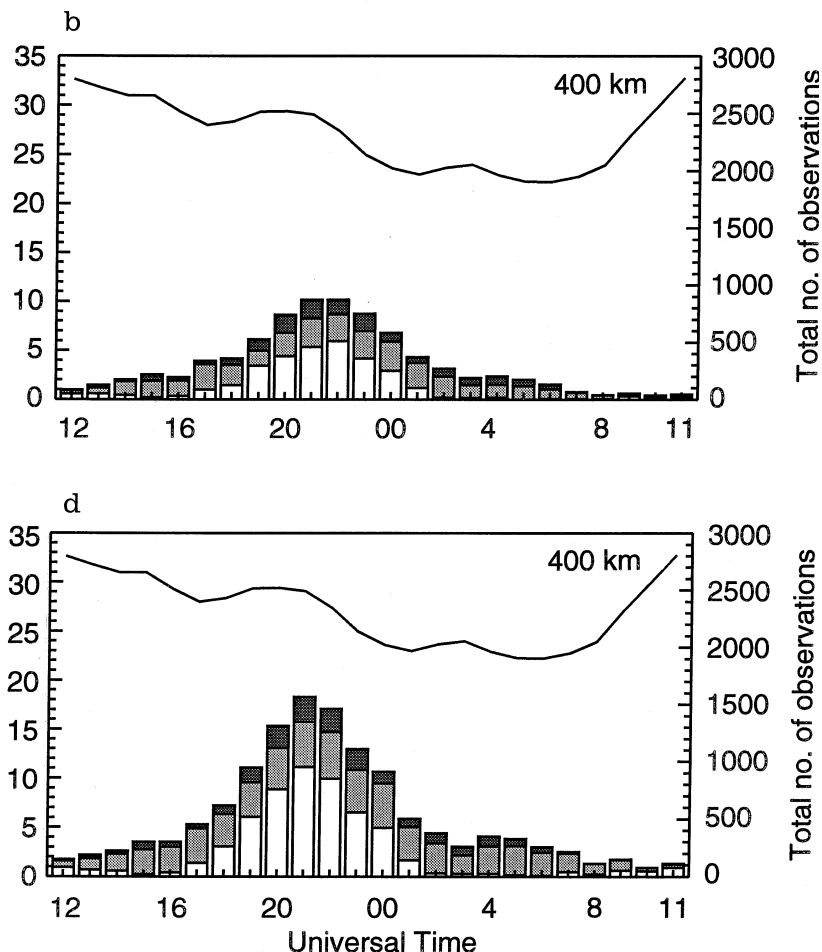

Fig. 7a-d. Diurnal distributions of upflow simultaneous with ion frictional heating events at a 300 and b $400 \mathrm{~km}$. c same as Fig. 1c, d same as Fig. 1e

since the ion temperature varies little over time scales of the order of days (Davies et al., 1997).

A crude comparison of Fig. 7a, b with Figs. 1c, e, included as Fig. $7 \mathrm{c}$, d, suggests that perhaps $50 \%$ of upflows occur during intervals of enhanced ion temperature. Furthermore, the proportions of the different event types are unchanged, indicating that the presence, or not, of enhanced ion temperature has no bearing on the type of upflow, as defined by the selection criteria.

At $400 \mathrm{~km}$ altitude the total number of observations was precisely 55719 , from which 3322 upflow events were identified. Of these, $60 \%$ were simultaneous with an enhanced ion temperature. Similarly, at $300 \mathrm{~km}$ altitude approximately $50 \%$ of upflows occurred simultaneously with elevated field-parallel ion temperatures. Numerical studies of field-aligned subauroral ion drift events (SAIDs) indicate that the response of the fieldaligned ion drift velocity to an increase in the F-region ion temperature is near-instantaneous, the field-aligned flow acting to redistribute the plasma to attain a new equilibrium scale height (Heelis et al., 1993). Thus we might expect to detect ion heating and field-aligned ion flow within the same post-integration period.

In summary, some $50 \%$ to $60 \%$ of upflows are associated with intervals of ion heating, which results primarily from frictional contact with the neutral atmosphere. This observation is true at least between 300 and $400 \mathrm{~km}$ altitude, where events of ion heating can be readily identified. This observation is in general agreement with the estimation of Keating et al. (1990), namely, that about half of the upflows identified by them when the ion temperature was enhanced. Furthermore, the implication is that perhaps $40 \%$ to $50 \%$ of $\mathrm{F}$ region ion upflows are not associated with ion heating.

\subsection{Upflows and electron temperature}

Several authors have demonstrated that an enhanced electron temperature may act in concert with a high ion temperature to generate upflows (e.g. Winser et al., 1989), whereas others (e.g. Wahlund et al., 1992; Foster and Lester, 1996) have indicated that upflows can sometimes be attributed to enhanced electron temperatures alone. A number of mechanisms can lead to heating of the electron population, for example EUV energization, E-region electron turbulent heating, particle precipitation and high-altitude ion-acoustic instabilities. These processes can lead to upward ion acceleration through thermal expansion or field-aligned electric fields.

To examine the statistical relationship between enhanced electron temperatures and ion upflows, an appropriate base value against which to identify elevated temperatures is required. It is inappropriate to derive an "average" electron temperature for a single experi- 
ment run, as was done for ion temperature, since the electron temperature is primarily dependent on solar flux and hence exhibits large diurnal fluctuations. Instead, median values of electron temperature, derived from distributions categorised according to altitude, UT, season and solar cycle, were calculated and used as a basis against which to measure electron temperature enhancements.

Diurnal upflow distributions were then derived for events where the electron temperature enhancement exceeded a specified threshold. An arbitrary value of $100 \mathrm{~K}$ was adopted; to a crude approximation, an electron temperature increase of $100 \mathrm{~K}$ would have a similar effect on the plasma pressure as an increase in ion temperature of the same magnitude.

Figure 8 illustrates the diurnal distribution of upflows at $400 \mathrm{~km}$ altitude that were concurrent with either an elevated electron or ion temperature, or both. The form of the distribution is clearly comparable with that of Fig. 1e, with similar proportions of the different event types evident. Hence the events represented in Fig. 8 are a characteristic subset of all observed upflows. A quantitative examination of the data revealed that about $80 \%$ of all upflows detected at $400 \mathrm{~km}$ altitude occurred during intervals when either or both the ion or electron temperature was enhanced.

These results are consistent with the more qualitative conclusions of Keating et al. (1990), where they examined the relationship between large upward field-aligned fluxes at $400 \mathrm{~km}$ and ion temperature at $200 \mathrm{~km}$, the observations being further categorised according to electron temperature at the lower altitude. These authors concluded that more upflow events occurred when both ion and electron temperatures at lower

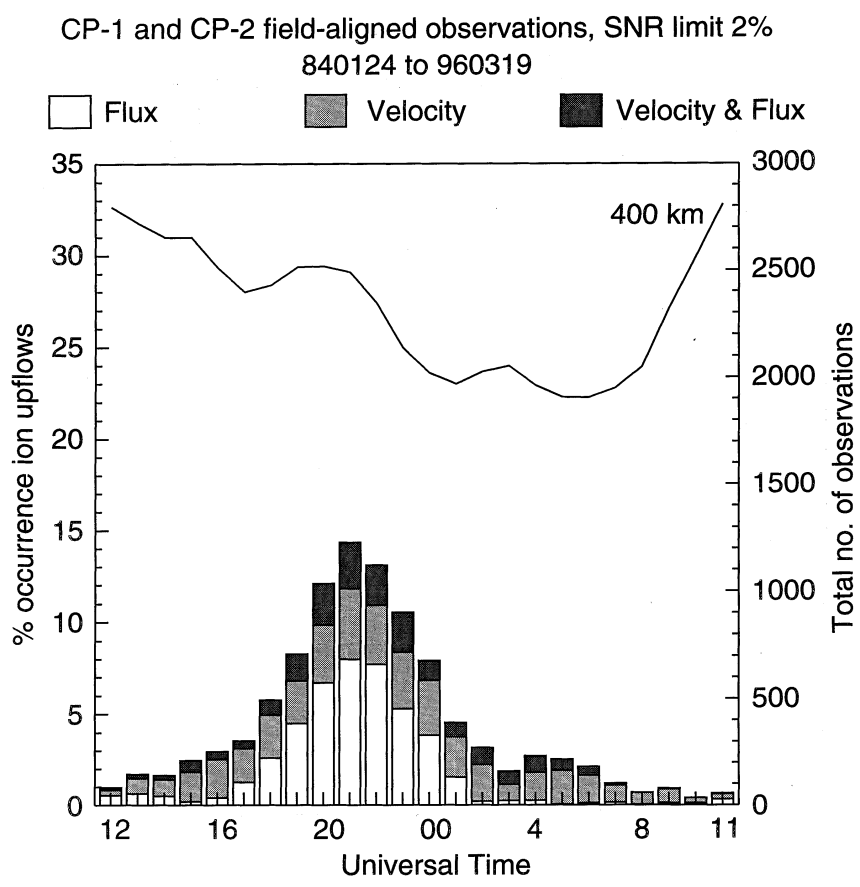

Fig. 8. Diurnal distribution of upflows $(400 \mathrm{~km})$ simultaneous with either an enhanced ion or electron temperature altitudes were higher than normally observed. Furthermore, measured upward fluxes were typically greater at such times. Although Keating et al. (1990) considered large upward fluxes as a function of electron temperature at a lower altitude, there was no suggestion that upflows should not be associated with ion or electron heating at the same altitude. Indeed, case studies have revealed that upflows and enhanced plasma temperatures occur simultaneously at the same height (Jones et al., 1988; Wahlund et al., 1992; Foster and Lester, 1996).

However, there are problems inherent in determining ambient electron temperatures against which to measure enhancements. Changes in electron temperature were measured according to differences between observed and median values, the latter based on EISCAT CP-1 and CP-2 observations between 1984 and 1996. Therefore, local enhancements in electron temperature would not be detected if the current "ambient" temperature was sufficiently greater than the median value. An example of such was apparent in CP-1 observations from October 27, 1988 (not illustrated). During this experiment, transient electron temperature enhancements of well over $100 \mathrm{~K}$ were detected at a time when upward fluxes exceeded $10^{13} \mathrm{~m}^{-2} \mathrm{~s}^{-1}$. However, the "typical" value of electron temperature at $400 \mathrm{~km}$ altitude for this time, as used in the previous investigation, was greater than $2100 \mathrm{~K}$. Hence the local electron temperature enhancements would not have been detected. Furthermore, the study was restricted to search for upflow and heating events which occurred at the same altitude. Keating et al. (1990) indicated that enhanced ion and electron temperatures at the lower altitude of $200 \mathrm{~km}$ can affect the number of upflows at $400 \mathrm{~km}$. Moreover, acoustic turbulence at high altitudes can greatly increase the electron temperature, leading to upward ion acceleration by enhanced electric fields (Swift, 1965; Papadopoulos, 1977; Forme et al., 1993; Wahlund et al., 1993). Upward flow at lower altitudes may result from a modified pressure gradient. Given these possibilities, and the results of the present study, it is surmised that the majority of upflows are associated with intervals of enhanced ion or electron temperature, although not necessarily at the altitude where the upflow is observed.

\section{Summary and conclusions}

The results of a statistical study of events of enhanced ion upflow have been presented. The study employed Fregion observations from EISCAT $\mathrm{CP}-1$ and $\mathrm{CP}-2$, covering a period of more than twelve years, and over five years of CP-7 topside measurements. The investigation has followed on from and extended the analysis performed by Keating et al. (1990), collating data from a far greater period of time and covering a wider range of altitudes. Initial results indicated a higher occurrence frequency of large field-aligned plasma flows in the evening sector, in agreement with the work of Keating et al. (1990). However, the inclusion of vertical obser- 
vations up to $800 \mathrm{~km}$ altitude revealed that the frequency of upflows increases steadily with height, whereas the study of Keating and co-workers suggested that the peak occurrence maximised between 400 and $500 \mathrm{~km}$ altitude. The present analysis also established that vertical observations are, in general, affected by the meridional component of ion velocity, which itself exhibits a strong diurnal variation.

The current study also revealed a pronounced seasonal dependence of upflow occurrence, with a greater frequency of IUEs during the winter months at 350 and $400 \mathrm{~km}$ altitude. It was also remarked that the large data set employed in the present study reduced the influence of "anomalous' intervals such as the July 1987 period noted by Keating et al. (1990).

The large data set, comprising EISCAT observations from more than $12 \mathrm{y}$, allowed the variation of upflow occurrence to be examined over a complete solar cycle. It was demonstrated that more events were observed during greater solar activity. Furthermore, the shape of the upflow distributions varied markedly with solar cycle. During solar minimum, the diurnal distributions tended to be much flatter, with less pronounced nightside maxima and more day-side events. Hence it is apparent that the three-year data set considered by Keating et al. (1990) would have introduced selection effects into the study. Moreover, it was revealed that the type of upflow likely to be detected is dependent on solar cycle; during active solar conditions, the majority of events exceeded the specified flux threshold only, whilst during quiet solar conditions only the velocity threshold was exceeded.

Finally, the dependence of upflows at $400 \mathrm{~km}$ altitude and enhancements in ion and electron temperatures was considered. It was demonstrated that between $50 \%$ and $60 \%$ of upflows occurred during intervals of enhanced ion temperature, and perhaps $80 \%$ were simultaneous with an elevated ion or electron temperature.

A number of ion acceleration mechanisms have been described which operate in the auroral ionosphere, as reviewed by, for example, Rodger et al. (1990) and Foster (1997). These processes generally pertain to heating of the plasma, and subsequent thermal expansion, during active auroral conditions. Large perpendicular electric fields can lead to frictional heating of the ions (e.g. Rees and Walker, 1968; St.-Maurice and Schunk, 1979; Davies, 1996), as well as turbulent electron heating in the E-region (e.g. Schlegel and St.Maurice, 1981; Robinson, 1992) and Joule heating of the neutral atmosphere (e.g. Cole, 1962; Jones et al., 1988). Bulk electron heating may also result from particle precipitation, both through collisions (Whitteker, 1977) and enhanced "anomalous" resistivity in the presence of field-aligned-current-induced instabilities (Wahlund et al., 1992; Blelly et al., 1996). Lowfrequency plasma instabilities can be generated by a number of processes, including sheared convection flows (Ganguli et al., 1994), and may heat the ions transverse to the geomagnetic field direction, leading to outward acceleration by the magnetic mirror force (Suvanto et al., 1989).
The auroral ionosphere is a consistent and significant source of ions for the magnetosphere. Field-aligned ion upflows, consisting primarily of $\mathrm{O}^{+}$, are commonly detected, with fluxes of order $10^{13}$ to $10^{14} \mathrm{~m}^{-2} \mathrm{~s}^{-1}$ and velocities from tens of $\mathrm{m} \mathrm{s}^{-1}$ to a few $\mathrm{km} \mathrm{s}^{-1}$. The occurrence distributions of these upflows suggest that the acceleration mechanisms that drive them are primarily associated with disturbed auroral conditions.

Acknowledgements. We thank the Director and staff of EISCAT for providing the data used in this paper. EISCAT is an international facility supported by the national science councils of Finland, France, Germany, Japan, Norway, Sweden and the United Kingdom. C. Foster was supported by a studentship from the Particle Physics and Astronomy Research Council of the United Kingdom.

Topical Editor D. Alcaydé thanks A. Yau and S. Watanabe for their help in evaluating this paper.

\section{References}

Abe, T., B. A. Whalen, A. W. Yau, R. E. Horita, S. Watanabe, and E. Sagawa, EXOS D (Akebono) suprathermal mass spectrometer observations of the polar wind, J. Geophys. Res., 98, 11 191, 1993.

Arnoldy, R. L., K. A. Lynch, P. M. Kintner, J. Vago, S. Chesney, T. E. Moore, and C. J. Pollock, Bursts of transverse ion acceleration at rocket altitudes, Geophys. Res. Lett., 19, 413, 1992.

Bates, H. F., Atmospheric expansion from Joule heating, Planet. Space Sci., 22, 925, 1974.

Blelly, P.-L., A. Robineau, and D. Alcaydé, Numerical modelling of intermittent ion outflow events above EISCAT, J. Atmos. Terr. Phys., 58, 273, 1996.

Chappell, C. R., The terrestrial plasma source: A new perspective in solar-terrestrial processes from Dynamics Explorer, Rev. Geophys., 26, 229, 1988.

Cole, K. D., Joule heating of the upper atmosphere, Aust. J. Phys., 15, 223, 1962.

Davies, J. A., Ion frictional heating in the high-latitude ionosphere, PhD Thesis, University of Leicester, UK, 1996.

Davies, J. A., M. Lester, and I. W. McCrea, A statistical study of ion frictional heating observed by EISCAT, Ann. Geophysicae, 15, 1399, 1997.

Davies, J. A., M. Lester, and I. W. McCrea, Correction to "A statistical study of ion frictional heating observed by EISCAT", Ann. Geophysicae, 16, 477, 1998.

Davies, K., Ionospheric Radio, Peter Peregrinus Ltd., London, 1990.

Du Castel, F., and G. Vasseur, Evaluation des performances d'un sondeur ionesphérique a diffusion incohérent, Ann. Telecommun., 27, 239, 1972.

Forme, F. R. E., J.-E. Wahlund, H. J. Opgenoorth, M. A. L. Persson, and E. V. Mishin, Effects of current driven instabilities on the ion and electron temperatures in the topside ionosphere, J. Atmos. Terr. Phys., 55, 647, 1993.

Foster, C., Auroral ion upflows in the F-region and topside ionosphere, PhD Thesis, University of Leicester, UK, 1997.

Foster, C., and M. Lester, Observations of nightside auroral plasma upflows in the F-region and topside ionosphere, Ann. Geophysicae, 14, 1274, 1996.

Ganguli, G., M. J. Keskinen, H. Romero, R. Heelis, T. Moore, and C. Pollock, Coupling of microprocesses and macroprocesses due to velocity shear: an application to the low-altitude ionosphere, J. Geophys. Res., 99, 8873, 1994.

Ghielmetti, A. G., R. G. Johnson, R. D. Sharp, and E. G. Bailey, The latitudinal, diurnal and altitudinal distributions of upward flowing energetic ions of ionospheric origin, Geophys. Res. Lett., 5, 59, 1978. 
Heelis, R. A., G. J. Bailey, R. Sellek, R. J. Moffett, and B. Jenkins, Field-aligned drifts in subauroral ion drift events, J. Geophys. Res., 98, 21493, 1993.

Jones, G. O. L., P. J. S. Williams, K. J. Winser, M. Lockwood, and K. Suvanto, Large plasma velocities along the magnetic field line in the auroral zone, Nature, 336, 231, 1988.

Keating, J. G., F. J. Mulligan, D. B. Doyle, K. J. Winser, and M. Lockwood, A statistical study of large field-aligned flows of thermal ions at high latitudes, Planet. Space Sci., 9, 1187, 1990.

Klumpar, D. M., Transversely accelerated ions: An ionospheric source of hot magnetospheric ions, J. Geophys. Res., 84, 4229, 1979.

Liu, C., J. L. Horwitz, and P. J. Richards, Effects of frictional ion heating and soft-electron precipitation on high-latitude Fregion upflows, Geophys. Res. Lett., 22, 2713, 1995.

Lockwood, M., Thermal ion flows in the topside auroral ionosphere and the effects of low-altitude, transverse acceleration, Planet. Space Sci., 30, 595, 1982

Loranc, M., W. B. Hanson, R. A. Heelis, and J.-P. St.-Maurice, A morphological study of vertical ionospheric flows in the highlatitude F-region, J. Geophys. Res., 96, 3627, 1991.

McCrea, I. W., M. Lester, T. R. Robinson, N. M. Wade, and T. B. Jones, On the identification and occurrence of ion frictional heating events in the high-latitude ionosphere, J. Atmos. Terr. Phys., 53, 587, 1991.

Papadopoulos, K., A review of anomalous resistivity for the ionosphere, Rev. Geophys. Space Phys., 15, 113, 1977.

Rees, M. H., and J. C. G. Walker, Ion and electron heating by auroral electric fields, Ann. Geophyscae, 24, 293, 1968.

Robinson, T. R., The effects of the resonance broadening of FarleyBuneman waves in electrodynamics and heating in the auroral E-region, J. Atmos. Terr. Phys., 54, 749, 1992.

Rodger, A. S., R. J. Moffet, and S. Quegan, Review paper: the role of ion drift in the formation of ionization troughs in the midand high-latitude ionosphere - a review, J. Atmos. Terr. Phys., 54, 1, 1992.

St.-Maurice J.-P. and R. W. Schunk, Ion velocity distributions in the high-latitude ionosphere, Rev. Geophys. Space Phys., 17, 243,1979

Schlegel, K., and J.-P. St.-Maurice, Anomalous heating of the polar ionosphere by unstable plasma waves: 1 . Observations, $J$. Geophys. Res., 86, 1447, 1981.

Suvanto, K., M. Lockwood, and T. J. Fuller-Rowell, The influence of anisotropic F-region ion velocity distributions on ionospheric ion outflows into the magnetosphere, J. Geophys. Res., 94, 1347, 1989.

Swift, D. W., A mechanism for energizing electrons in the magnetosphere, J. Geophys. Res., 70, 3061, 1965.

Ungstrup, E., D. M. Klumpar, and W. J. Heikkila, Heating of ions to superthermal energies in the topside ionosphere by electrostatic ion cyclotron waves, J. Geophys. Res., 84, 4289, 1979.

Wahlund, J.-E., and H. Opgenoorth, EISCAT observations of strong ion outflows from the F-region ionosphere during auroral activity: preliminary results, Geophys. Res. Lett., 16, 727, 1989.

Wahlund, J.-E., H. J. Opgenoorth, I. Häggström, K. J. Winser and G. O. L. Jones, EISCAT Observations of topside ionospheric ion outflows during auroral activity: revisited, J. Geophys. Res., 97, 3019, 1992.

Wahlund, J.-E., H. J. Opgenoorth, F. R. E. Forme, M. A. L. Persson, I. Häggström, and J. Lilensten, Electron energization in the topside auroral ionosphere: on the importance of ionacoustic turbulence, J. Atmos. Terr. Phys., 55, 623, 1993.

Whitteker, J. H., The transient response of the topside ionosphere to precipitation, Planet. Space Sci., 25, 773, 1977.

Williams, P. J. S., and A. R. Jain, Observations of the high-latitude trough using EISCAT, J. Atmos. Terr. Phys., 48, 423, 1986.

Wilson, G. R., Kinetic modelling of $\mathrm{O}^{+}$upflows resulting from ExB convection heating in the high-latitude F-region ionosphere, J. Geophys. Res., 99, 17453, 1994.

Winser, K. J., G. O. L. Jones, and P. J. S. Williams, A quantitative study of the high latitude ionospheric trough using EISCAT's common programmes, J. Atmos. Terr. Phys., 48, 893, 1986.

Winser, K. J., A. Farmer, D. Rees, and A. Aruliah, Ion neutral dynamics in the high-latitude ionosphere - 1st results from the INDI experiment, J. Atmos. Terr. Phys., 50, 369, 1988.

Winser, K. J., G. O. L. Jones, P. J. S. Williams, and M. Lockwood, Observations of large field-aligned flows of thermal plasma in the auroral ionosphere, Adv. Space. Res., 9, 57, 1989.

Yau, A. W., B. A. Whalen, W. K. Petersen, and E. G. Shelley, Distribution of upflowing ionospheric ions in the high-latitude polar cap and auroral ionosphere, J. Geophys. Res., 89, 5507, 1984.

Yau, A. W., E. G. Shelley, W. K. Peterson, and L. Lenchyshyn, Energetic auroral and polar ion outflow at DE-1 altitudes: magnitude, composition, magnetic activity dependence, and long-term variations, J. Geophys. Res., 90, 8417, 1985. 